\title{
Stepping Stones to an Information Society
}

\author{
Jiří Zlatuška \\ Masaryk University, Faculty of Informatics \\ Botanická 68a, 60200 Brno, Czech Republic
}

\begin{abstract}
The information revolution is radically transforming many patterns along which society and enterprises have traditionally worked. These changes do not bring just minor technological improvements, but indeed a fundamental transformation of our industry-based society into an information-based one. The changes are most visible and documented within the business world, but the synergy between technological and social shifts does not stop there. In this paper we try to identify and summarize key trends and challenges which this development puts before us.
\end{abstract}

Invited paper appearing in: Proc. SOFSEM'97, Bartošek, M., ed., (Milovy, Czech Rep., November 22-29, 1997), Springer LNCS, 1997, pp. 349-372.

\section{Introduction}

The development of information processing and communication technologies based on the digital computer and digital information representation and manipulation has made the closing decades of the millennium also the beginning of the new "Age of Information". It is ushered by the information revolution caused by the rapid change of the technological base used by the developed society. Information storage, manipulation, and distribution have been part of the history of human civilization, and a fundamental element of societal development both in the spiritual and production sense. The development of writing from cave paintings within the span of c.20000 BC to c.4000 BC introduced discrete representation into the way in which human memory was recorded or various forms of communication were utilized, followed closely by the use of linear representation (c.1500 BC) and alphabetic writing (shortly after $1000 \mathrm{BC}$ ). This coincided with early civilizations and the development of viable agriculture. When compared to block-print known to the Chinese already sometime more than 2000 years ago, Gutenberg's invention of the movable type (1448) can be likened to a "universal machine" of the printed text (a difference similar to the difference between a simple calculator and a programmable universal computer). The movable printing press allowed to reassemble components needed for book printing into configuration of any sort, which made book publishing economically much more viable when compared to manual hand-copying by monks. This triggered an explosion of book production (some 20 million books are estimated to have been printed within the first 50 years, more than the number of books produced ever before that), led to general literacy and school system, and made it possible for the industrial revolution to have both sufficient number of knowledgeable inventors, as well as the uniformly educated workforce needed for the industrial era. 
The development and massive utilization of digital computers (electronic computers, as we should stress in the year of the 100th anniversary of Thomson's discovery of the electron) and computer-based communication networks within the last few decades have been causing fundamental change in the character of our society. There are many aspects of this process which make it possible to identify the coming of an "information society" as a result of the computer revolution, in an analogous way to the "industrial society" which superseded the agricultural one as a result of the industrial revolution. Computers and telecommunication devices are becoming ubiquitous appliances used in nearly any area of human activity and they are the basis of the new infrastructure. The computer, once a huge technological monstrum dimming the street lights when having been switched on, has become a tiny appliance found everywhere from washing machines, car engines, telephones, or ordinary "things" of everyday use such as hotel doors or personal ID cards. We are not paying attention to them in many cases any longer, simply expecting that they would do the "information-enriched" job they are supposed to, similarly to having stopped paying attention to the way the electrical wiring is prepared in buildings so that our industrial devices can be powered up wherever we need them.

The technical advances make it possible to think realistically of petaflop computers or terabit networks to appear very soon for affordable prices. Computer chips keep obeying the so-called Moore's law, which means doubling the performance each 18 months, or halving the price under constant power. The cost per communicated bit falls down much faster, allowing for forecasts for doubling the total network bandwidth within as short as 8 months [18]. With petaflop computers and terabit networks coming soon (note that estimated $1 \mathrm{M}$ increase can be achieved without changing the already installed fiber-optic cable capacity), it is realistic to assume that computing becomes ubiquitous and the price of networking virtually disappears. Most popular software producers already take advantage of the fact that the worries to optimize for space or time belong to yesterday-and majority of today's customers seem quite willing to pay the price for it, even though the asymptotic benefits have not really materialized for them yet.

The story is however not just about computers as convenient appliances useful for embedding into various sorts of devices. On a more fundamental scale, it is about the increasingly important function of information as the main driving force of the post-industrial stage of the developed nations and deep changes in the character and organization of social and economic life induced by contemporary information technologies. The net effect of these changes is indeed revolutionary in its profound, pervasive, and permanent nature which transgresses just mere improvements of the way how to perform calculations (see also an earlier [21], or, e.g., [49]).

The nature of the changes has a variety of facets, which result from various rôles in which the use of information shifts the emphasis from producing and manipulating material goods to manipulating knowledge, from processing the "hard" to processing the "soft", or perhaps from creating the wealth to 
generating and manipulating knowledge. This concerns a range of issues from manipulating bits and digital information with all the consequences to human communication, perception, and understanding [39], economic activities, organizing and conducting business, and changes induced by networking [55], [24], the impact of new technological changes [12], to the overall pattern of changes which accompany the end of the industrial age [57] and the increased dominance of services on the expense of traditional manufacturing [7].

\section{The pattern of change}

The influence of the information revolution on businesses and industrial enterprises has manifested itself clearly enough over past several decades ([32] even argues for "organizational informatics"). None of these changes is limited to just "efficiency" of production, but rather to very far-reaching changes in the functional organization and structure, resulting in a real change of the "quality" as well. New organizations and new organizational forms exist in parallel with the old ones. The changes do not constitute any complete replacement. The new forms co-exist and compete with those inherited from the past. Various observers have put emphasis on slightly differing points when identifying the principal features of the change.

Alvin Toffler argues for the "third wave" constituting a development superseding the old "second wave" society of the industrial age [57]. The economies of scale, mass production, standardization, synchronization, concentration and centralization are the key features growing through the fabric which the society is contained in. The third wave society introduces a "practopian" future favoring individual difference, de-massification, variety of possible lifestyles, working and production patterns, and the value of individual skills and innovations. Toffler's third wave comes with the "prosumer" (merging production with consumption), with the change in the organizational structure from informationmonopolizing hierarchies to information-spreading matrixes or to a host of other "flexible" organizational forms suiting individual business needs, and with the diminishing rôle of marketing and mediating agents. These changes have been enabled by modern information technology, but they in no means are constrained by it - this is, in fact, one of the reasons why Toffler would not say "computer" or "information" revolution, but rather the "third wave" as a concept with much wider applicability. Within the U.S., Toffler argues, the third wave arrived in the decade following 1955, within the time when the whitecollar and service workforce outnumbered the blue-collar workers, followed soon by other developed countries.

Don Tapscott comes with a concept linked very tightly with the digital nature of information processing and computer-based communication [55], and draws very close analogies between information technologies (IT) based on digital technology, both hardware and software, and the transformation of the business, and of social, and political life. Among the themes Tapscott introduces, one can find "digitization", "virtualization", "molecularization", "inter- 
networking", "convergence", or "prosumption", which relate very closely to a majority of concepts introduced by Toffler. Digital, or bit-based products are becoming the major product and material within the economy (this trend is also illustrated indirectly by the shift in spending proportion between packaged software and hardware, which changed from 7 cents for software per \$1 spent on hardware to the current ratio of 1:1 according to [37]).

A related set of problems has been tackled by Stan Davis [10] who studied the change in the meaning of time, space, and mass, and introduced the term "mass customization" assuming a market where "customer's individualized needs are satisfied with mass-produced goods, and the customizing occurs at instantaneous speed in the matching-up process". This relates to Tapscott's "real-time economy" and Toffler's "just-in-time" or "on-demand" production with prosumer controlling the features of the resulting product.

The economy and means of production changes also bring about changes in organizational structure. This concerns the team-based organization [35], the matrix structure [57], the hypertext organization and the task-force use [40], the internetworked enterprise [55], or Quinn's infinitely flat, spider's web, or starburst, or inverted organizations and the focus on the functional "core competencies" of network organizations [44]. The resulting "virtual organization" [43] allows for flexible outsourcing of activities, encourages the "molecularization" [55] or "cottage industries" [57]. During the early nineties, several techniques have been introduced that enable organizational change and thus allow existing institutions to accommodate their organizational structure to their changing environment, even though their rate of success is rather debatable [14]. Although the use of information and communication technology is clearly a catalyst and a mediator of the change, some of the impacts are still not well enough understood, such as the "productivity paradox" (see [25] and [54] for more discussion on this).

The networking organizational paradigm extends beyond the individual organizations. The molecularization of the production units, subcontracting, and the use of internetworked organizational structures make the difference between individual company and a productive chain, or between a vendor and a consumer, a fuzzy one, by unifying these configurations into a new entity as it has been the case with blurred distinction between the producer and the consumer. The same applies to the virtual or niche markets where the community aspects of the network coalitions, including loyalty to the networks rather than to individual companies, help to create a very dynamic environment reinforcing the returns for everybody who participates in it $^{1}$. The chaotic nature of these

\footnotetext{
${ }^{1}$ An unpublished report by Donald Hicks of University of Texas commissioned by the State of Texas discovered that the average half-life of businesses dropped by half during past 22 years, indicating that the economic churn may be one of the key factors in establishing long-term stability. Surprisingly enough, areas with the shortest life expectancy of businesses, such as Austin, are having the fastest-growing job base and the highest wages-high business-mortality rates are good for economic health. The rate of innovation helps to explain this. ([59])
} 
processes, the continuing churn in structure, membership and functional linkages, the power of creative destruction within decentralized dynamic networkbased systems generate a "net gain" from which every participant benefits [24]. Communication and networking becomes the key element of success here. The multiplicative effect of the network suddenly makes the contribution of an individual computer negligible. The history repeats itself: Had it not been for things other than just the ability to carry out numerical computations, the computer would have remained a scarce item in the post WW II world. Within the information-based world of today, it is the ability to network and to communicate information rather than just to process it, which makes computers the agents of the revolution we participate in.

The change in the working environment generates profound changes in other aspects of social life as well. They change the rôle of the individual within the information-age institutions, the rapid pace of change and makes it necessary for the individuals to adapt several times within their lifetime to change in their work and lifestyle, and to incorporate the element of continuous learning into the productive life. Informatics is emergeing as a new methodology of science and technology, accompanying the theoretical and experimental ones [22]. The way of how democratic societies function will surely transform. A democratization of information access and generation, enhancement of the individual's participation, and economic feasibility to effectively care about minority interests, establish themselves as the working modes of the society structure, eventually breaking the neck of the hierarchical bureaucracy as it has been the case within successful companies.

\section{The Information Economy}

Information becomes both an essential product and indispensable commodity for functioning of the modern society. There is a trade-off between the mass and the information in efficient functioning of companies in the information age which is similar to the trade-offs between space and time in the complexity theory. Communication links and virtual market communities allow to eliminate intermediaries, and to adjust the mismatch between production and consumption in terms of quantity, quality, and the time of delivery and/or production. The communication channels become a substitute for storage houses and store shelves which would otherwise be necessary. The instant knowledge of the volume of sales performed, the accessibility of information about the amounts of goods still available on the department store shelves (with built-in intelligence comparable by amount and size to that needed in an ordinary smart card), the possibility of combining the information gathered about the customer (leaving aside the privacy issues for the moment) with targeted marketing-each of these contribute to eliminating some portion of the production and/or distribution facilities, to lowering the volume of mass production of "ready-made" goods, and to substitute these by just-in-time production of products which are mass-customized to the needs of the individual customer. 
Plentiful examples of this can be found almost everywhere. Motor vehicle factories can produce passenger cars in such a way that a desired setting of some 100 features can be chosen by the customer as in independent options (or in most cases independent). The potential number of variants, exponential in number of features, thus exceeds the real production possibilities, making the traditional production line very unpractical. Efficient handling of information concerning customers requirements, the knowledge immersed into the workflow organization, and a radical reorganization of the causal flow of actions makes it possible to produce a car as if custom-made for a particular customer, yet with the efficiency not lower than that of blind massproduction of the first half of the 20th century. The effective use of knowledge within the production process results internally in abolishing the beat of the production line as a central clock of every worker's work, and substituting it by automated work of robots fed on-line with the necessary data, and the workers performing individualized special tasks when needed. The resulting process effectively implements late-binding within the factory work organization, using a lazy-evaluation computational model as contrasted with the eager-evaluation strategy of the Taylorian production line model performing brute-force search, or product generation for storage from which the customer chooses later.

The "Levi's Personal Pair Jeans" has been a service established by a tiny network-based company called Custom Clothing Technology for Levi Strauss in order to link the retailers, cutters, stitchers, and washers in order to produce a pair of jeans made exactly to the measures taken from the customer and inserted into a networked computer. Within a matter of days the jeans made to perfect fit are delivered by Federal Express. The network becomes a device for mass customization and late-binding lazy-mode style production. No production for storage is needed but this is still not all. In the traditional massproduction style, $75 \%$ of cost are in distribution, not manufacture, and more than $70 \%$ of women who purchase jeans are unhappy with the fit [55]. These factors are almost completely eliminated as well as the seasonal sales of unsold stock.

Journals and other publications can be mass-customized for a particular subscriber or a special group of them. Major popular journals are published in mutations specialized for some geographical area or even a city region, such as the Time magazine differentiating in some details of itself even within various parts of Los Angeles, or the Farm Journal mixing individualized issues according to the reading profiles and individual interests in agriculture production or advertising for the customer to which it will be delivered [10]. McGraw-Hill offers its academic customers custom-made textbooks printed according to their individual requirements. Electronic web sites which major newspapers or journals run as an extra bonus, can not only feature up-to-date news flashes (the small guys need not necessarily be the slowest - the Czech electronic daily newspaper Neviditelny pes for example managed to report the take-off of U.S. bombers from Guam for 
the first strike in the Gulf war several hours before the news appeared on $\mathrm{CNN}$, thanks to a virtual editorial board which spans the globe ${ }^{2}$ ), but also the latest news selection prepared so that it fits the pre-defined user's profile.

Federal Express, a package delivery company with 50\% market share in the U.S., has been expanding its customer base in a major part because of the use of a sophisticated real-time electronic tracking which provides on-line a detailed information about the position of every single parcel, and even sharing this information with the customer. The company plans to use smart labels equipped with a single-use chip for active package identification, making the "information on the move" a part of the shipping business.

Clearly, the material aspect is no longer what makes a product interesting, but rather the information or knowledge contents in it. In fact, knowledge may be the only meaningful resource overshadowing the traditional production factors such as capital, labor, land, or raw materials [13]. The emphasis on the generation of material or financial wealth has been replaced by the emphasis on processing the knowledge. The number of various bit patterns which can be stored on a floppy is bigger than the number of elementary particles in the observable Universe. Each of them can turn out to be a product-maybe worthless, maybe a future killer application. The cost of reproduction of the digital product is close to nil, with no quality loss. What matters is the "inspiration", not some repetitive of reproducible labor ("perspiration" remains reserved for robots). Successful companies today do not depend on huge capital investments or production plants. It is rather the "knowledge worker" of theirs who matters most ${ }^{3}$.

\section{Building blocks of the new organizational structures}

The organizational structure assumes new forms which emerge with dynamic and innovative organizations, either new ones or those ones who transform the way they function. These elements of the new structure are by no means a panacea. More than that, they represent a trend which can be observed more and more frequently, and which symbolizes the new structures enabled by new technologies and new ways of doing business. Some of them are to be listed in this section.

\footnotetext{
${ }^{2}$ The politicians are, however, sometimes very reluctant to accomodate to these changes. The advisor to the otherwise very market-favoring PM would publicly label the web daily newspaper as "unofficial" media, when explaining why the government claimed having had no knowledge of news which were already given enough publicity in it-incidentally just a few days after the number of readership hits of this newspaper exceeded 1 million.

${ }^{3}$ There are also negative aspects of this. Consider problems of financial guarantees of service-type companies towards their customers, and the amount of recoverable capital available in case of bancruptcy.
} 


\section{Disintermediation}

Disintermediation is a result of direct relationship between consumers and producers where intermediate steps or processes make it more difficult to use efficiently the information feedback which occurs when a close loop is engaged. This is an important element when production on demand is used. This trend is predominantly represented by companies selling CDs, concert tickets, or books. In these applications the network provides an environment in which the consumer visits a virtual store with functions that are similar to the activities one could be interested in when physically visiting a store (e.g., book browsing and book reading capabilities in the National Academy Press bookstore at http://www.nap.edu/. Some additional enhanced features such as new publication notices, and readers contents evaluations such as those available at Amazon . com, are usually added to cuch a functionality.

Areas will remain where the consumer avoids the intermediary because no added value, no added knowledge, or information enrichment occurs. This applies to direct air ticket sales, direct booking of hotels, or direct arrangements of vacations by virtually visiting the places of interest and arranging what needs to be done. Travel companies will soon cease to be just selling points for travel tickets, and will transform themselves into businesses which depend on selling knowledge-dependent products ("meta-knowledge") which offer services, expertise, and structure, which would otherwise be very difficult to acquire.

Newspapers and news journals won't disappear either. They may not be needed any longer as a privileged source of information, because that is more easily available on the Net, but they will actually sell their work on selecting relevant pieces of news and arranging them conveniently to the reader. The meta-knowledge and meta-information structure can easily be worth more than the object of it (e.g., the TV Guide which publishes programs of American TV channels, has been having greater market value than either of the TV networks it reports on [10]).

\section{Convergence}

Convergence of key economic sectors as well as convergence of different technologies comes as a natural consequence of the fact that the product and/or mode of operation becomes digital. Services and products can merge one into another, creating new challenges and opportunities. Many of the professions of tomorrow, the products, and future industries do not exist today. Computing, communications, and contents traditionally used to be distinct areas of expertise, manipulation, and company activities. The technological base of each of them used to be clearly differentiable. There are plenty of examples of a trend to the reverse now.

Telephone, television set, and computer may shortly evolve into a single home appliance. There are products, either hardware or software, which already combine some of these functions. 
Web sites of major newspapers add more and more interactive features and perpetual news of the day updating, so that they resemble TV or radio (when the network bandwidth allows this, it will be difficult to differentiate between those and customized personal TV channels). TV stations run informative web sites which can allow the visitors to play voice messages of other visitors, or leave one's own comments for others (examples of this may be ABCNEWS.com chat column or CNN.com voice message corner for specific key stories). Electronic newspapers run discussion forums for their readers allowing to discuss issues related to newspaper contents or any topic in general-besides of the function of an electronic newspaper this also allows to establish a virtual community of interested readers.

\section{Virtualization}

Virtualization creates digital objects which substitute a real entity, causing the environment and the users to act as if the objects existed, with real effects and consequences. We can therefore introduce notions of, e.g., "virtual" institutions, staff, products, tools, services, markets, or appliances.

Virtual communities are formed by allowing sufficiently rich communication among the members of the community across the network. Physical proximity or temporal synchronization of communication by individual members is no longer an obstacle in forming an effectively working community. Groups with minority interests can more easily be formed as virtual ones, because most of the economic limitations of members' mutual interaction can be reduced next to nothing. The dynamics of virtual community formation depends on the interplay of attracting critical mass of members, user profiles and aggregation of vendors and advertisers giving rise to the amount of transactions and transaction categories [24]. In successful cases the combined impact amplifies the dynamics of increasing returns as a resonance-based effect within an otherwise chaotic system. The Amazon.com virtual bookstore has raised sales from \$ 0.5 million in 1995 to \$15.7 million in 1996, a 25\% monthly grow, creating a virtual community base of 180,000 customers from 100 countries worldwide. It is still in its infancy, though, with net balance in red numbers - a sign of being still within the aggregating phase of critical mass accumulation. (The total volume of electronic commerce has been around $\$ 600$ million in 1996, expected to grow to $\$ 66$ billion by 2000 , according to Forrester Research estimates.)

Virtual markets, virtual stores, virtual advertisement, and virtual jobs $(100 \%$ telecommuting or teleworking) correspond to activities performed over the net, without any physical presence which would otherwise be necessary. Virtual immigrants can perform work in overseas companies without leaving their home country (such as Indian programmers for U.S. software companies), evading immigration laws, work permits, and often also paying taxes.

Virtual universities can bring together the best professors (no matter where their physical home and/or place of work is) and the brightest students in order to network top-quality resources. Virtual students may also be interested in continuing education or enhancement/refreshment/updating their current 
proficiency level. (Example of the latter is the Michigan Virtual Automotive College at http://www.mvac.org/.)

Virtual communities also present a sociological phenomenon, not just a technological one. If the members of the community are to co-operate effectively, it is necessary to build certain level of trust among its memebrs, and it is not enough to merely verify the communication channels or the other party's identity (compare [15] on the importance of the level of trust for the overall structure and functioning of economic structures in various countries). From all possible obstacles, this may be the single one most difficult to overcome in reality. In the digital world, it is becoming easier to falsify then to verify the truth $^{4}$. Other interesting social contradictions related to the concept of virtual communities are raised in [45].

\section{Molecularization and decentralization}

Molecularization and decentralization represents a trend towards establishing a network-based economic and social interactions between small units in contrast to large industrial-age corporations. Flexibility of information flow patterns enabled by information technology use have made huge bureaucracies which represented an organizational skeleton between the top management and the line worker disappear. The structure whose principal function was to organize information flow and information filtering has lost its function and has become an obstacle. The decision power has moved down, creating a flat structure instead of a hierarchy. More independence in decision making allows to commission more work on a contractual basis. This may lay a foundation to an "invisible economy" based in a larger extent on the prosumers working within the "electronic cottage" environment as very much autonomous economic agents $[57]^{5}$.

The flexibility of digital information flow arrangement allows a liquidcrystal-like enterprise with elements of it able to act and reconfigure very flexibly, yet with a degree of structure where needed [55]. Similarly to that, "organizations without boundaries" [35] make flexible arrangement of the information flows which disregards the difference between the inside and

\footnotetext{
${ }^{4}$ See Web link http://www.chicago.tribune.com/news/current/schmich0601.htm for a recent amusing example of this where a Chicago Tribune column by Mary Schmich started to circulate the Internet as a commencement speech of Kurt Vonnegut at MIT. We may soon watch digitally fabricated news shots on TV news in the style of Forrest Gump. There are also tendencies going counter this: The news shots from the Boer War were actually made on Jersey island but the Gulf War was already converted by $\mathrm{CNN}$ into an on-line show which went for real.

${ }^{5}$ Although this trend is noticeable, the general tendency within the U.S. economy shows mixed patterns: According to 1993 U.S. Bureau of Census data, some $90 \%$ of the companies have fewer than 20 employees, but the total number of employees within them amounts to just $20 \%$ of the total employment and $17 \%$ of the net salaries payed. Companies with more than 500 employees represent $47 \%$ of total employed workforce, with net salaries $53 \%$ of the total.
} 
outside of an organization and allows the molecules diffuse through its outer membrane. This is already happening with the use of extranets. (Forrester Research has found in a recent study that extranets represent service which is demanded most from the Fortune 1000 companies.) Interaction patterns based on the object-oriented approach are another manifestation of this.

\section{Outsourcing and subcontracting}

Outsourcing and subcontracting together with the use of network relationships (internetworking), each of which are very closely related to molecularization, emerge as a new working paradigm. New products can be based on combining existing elements and fitting them together-a task much easier done within the digital world, in contrast to mechanical parts of industrial products. Within the educational sector the idea of virtual universities which provide "knowledge pointers" to sites which specialize in particular topics can provide the motivation for such an approach. A coherent outline of the use of the contracting paradigm applied to public education can be found in [26]. (For more cautious treatment of outsourcing in connection with development of software systems, see [54].)

\section{Globalization}

Globalization comes out as a natural consequence of the way in which the information and communication technologies make the difference in time and space to disappear (or mostly disappear). The Age of Information coincides with the Era of Globalization not just by coincidence-it is indeed the digital paradigm which makes both of them work.

Telecommunications based on telephone or telegraph allowed to overcome distance in space in point-to-point communication between people, and changed the psychology of communication and human interaction in this respect. Some of the consequences have been rather surprising and seemingly without causal relationship-e.g., it was the telephone which made building of skyscrapers possible and usable. Digital packet switching networks as invented by Paul Baran [2] and brought into being as today's Internet ([23] or [48] provide interesting historical accounts of early Internet development) are also not just connecting the computational power of computers, but changing the behavior of the society, as can be illustrated on the disputes over free speech, privacy issues, or individual responsibility.

The ability to deliver information in various formats and amounts across a uniform network environment without distortion or quality degradation (in contrast to analog communications), allows the communication environment to stretch the understanding of "same place" and "same time" and to multiply human ability to interact. E-mail already changed the topology of time in multiple dialogues which the user is continually engaged in, and noone would assume any longer that, e.g., both parties in a discussion must be both awake at the same time, or that engagement in a discussion within one circle prevents 
taking part simultaneously in another one, on a different topic. The structure of the economic and social interactions in network-based virtual communities are similarly no longer bound by physical proximity. The notions of "niche economy" or "economy of scope" are based on these liberating trends. They have become essential ingrediences of success of the fast-growing knowledge companies.

\section{Elements of transition}

The general trends are better noticeable with new companies and enterprises but the existing one are undergoing a process of adaptation as well. Although there is no universally accepted explanation of the productivity paradox (based on U.S. data, productivity growth in non-farm business has slowed down from $3 \%$ p.a. to $1.1 \%$ p.a. during the 70 's and 80 's, with noticeable complete stagnation during 80-82), there seems to be prevailing consensus that a key ingredient of the explanation has to do with the inadequacy of how information technology tools are used in obsolete organizational contexts.

It is not surprising that the use of computers in manufacturing has generated huge productivity advances. When human workers are being replaced by machines or robots, this is, after all, the simplest situation in which computers can boost productivity as measured in terms of the volume of production.

It is not so straightforward, however, to apply computers in administration and services, and in the context of "knowledge work" in general. These applications deal with information and task flows within the company structure, yet their potential also allows changing the very same structure as well. If new technology is to be introduced with efficiency it promises to deliver, it is necessary to reorganize the information structure, to identify the core elements of the organization, to establish a clear vision of the future of the organization, and to try to identify new opportunities within the organization rather than to try solve emerging crises.

Existing strategies have focused on various priorities within the transformational task. The general drive towards smaller companies is reflected in downsizing in various disguises ${ }^{6}$, ideally making the organization more efficient and more responsive to changes of its working environment. Making an organization work better under more potent technological conditions is the principal aim of reengineeing which aims at improving old processes (which mostly evolved due to history of events, not due to functional needs). Top quality management (TQM) is another approach focused on seeking perfectness in key areas related to quality of the function of the company.

\footnotetext{
${ }^{6}$ The Orwellian terminology used with very much the same meaning include: compressing, consolidating, demassing, dismantling, decomissioning, downshifting, rationalizing, reallocating, reassigning, rebalancing, redesigning, resizing, retrenching, redeploying, rightsizing, secondment, streamlining, or slimming down. (Most of these terms are taken from [14].)
} 
There is really no theory behind any of these strategies, and there are few, if any, credible studies of the real effect of either of them [14], [30]. Reengineering seems to be the most relevant of these as far as information technologies are concerned. One of the classical cases of its use was a project at IBM where the number of steps in the process from customer orders to sales was reduced from seven-day six-step process to two-step process taking just four hours. Chase Manhattan bank has been reported recently to have automated e-mail processing by having a program which processes $94-95 \%$ of the e-mails sent automatically, and the rest is dispatched for manual processing. This allowed to cut the time needed to process one e-mail message from 8-15 minutes when done manually, to under 1 second after this change. (The investment costs should return within 6 months.) The transformation strategies may not be everything what counts in this respect, and also other dimensions which take into account functioning of the user-machine interfaces should be given more attention. A case is made in [34] for such a "user-centered" design as a software-related part of the solution of productivity paradox problems.

Besides of the inadequate organizational structure, the reason for productivity stagnation in jobs equipped by IT may also come from the fact that the investment into information technologies is actually very slow to return, and majority of companies are still under-equipped. One possible explanation of the current unusually long period of low inflation, low unemployment, and prolonged economic growth in the U.S. (productivity increase of 3.4\% in 1995 and $3.8 \%$ in 1996 is unprecedented compared to 70's and 80's) is based on the idea that this is a result of 20 year investments into IT slowly beginning to generate returns. It is however too early to be able to say anything conclusive on this (see, e.g., [53] for very cautious arguments in this respect).

The pattern of investment into new technologies, the effect of learning curves, and the pace of technological adaptation can also be studied based on the experience of the industrial revolution as it is done in [19], even though the pace of change may be considerably accelerated. New technologies need substantial amount of capital investment which is essential for continuing growth. The returns on this investment take about two decades to start appearing. Dramatic differences are emerging between the opportunities available to qualified and unqualified workforce, high learning cost drives down productivity within timespan of about four decades, and the income differences between qualified and unqualified members of the society keep rising. The social consequences of these processes may be as dramatic as those which shake up company bureaucracies. Even though in the long run everybody will be better off, to arrive at this point will be as painful as it was the case before everybody gained from the industrial revolution: "Unskilled wages fall during initial stages of the Information Age. Twenty years elapse before this loss in unskilled wages is made up and about 50 go by before they cross their old path. Interestingly, during the early stages of the Information Age the stock market booms as it capitalizes the higher rates of return offered by the new investment opportunities. For many in the economy, though, waiting for the benefits 
of the technological miracles will be like watching grass grow; but grow it will. ... Thus, in the short run young, unskilled agents fare worst. In the long run the rising tide of technological change will lift everybody's boat." ([20]) The initial part of this scenario is very much consistent with the data on the current trends related to the effects of de-industrialization. Recent IMF study shows that the reduction of the share of civilian employment is declining worldwide (it started in late 60's in the industrial countries with Japan being the slowest to join this trend as late as in 73, and it started also in more advanced East Asian countries in late $80^{\prime} \mathrm{s}$ ) but this decline is accompanied by increased numbers of well-qualified jobs (information technologies, education, financial and legal services) [47].

When these effects are combined with the negative consequences of the majority rent-seeking efforts in the welfare states at the end of 20th century [4], the demographic trend in the developed countries, and the incompatibility of trade union bargaining mentality, with basic mechanisms of the information economy functioning [47], it is clear that the worst stirs, transformations, and shake-ups which the society faces will be much more dramatic than those faced by company bureaucracies. The increased emphasis on education, especially the continuing life-long education, may help to narrow the gap between those who get and who loose in the short time. Education will have to be run as an information-age business as well [63], and to create a virtual classroom [56] which everybody will be able to attend. There won't be just "learning organizations" but the society should become a "learning society" [17] as well. The multiplying effect, driven by the law of increasing returns, will form around virtual universities, and the synergy between academic research and the students transferring these state-of-the-art technologies into practical life may further catalyze future development and economic well-being. The conclusions of two major recent higher education system studies in the U.S. [5] and U. K. [38] support this claim. Information technologies also make it easier to accommodate for diverse educational opportunities compatible with the value of unique combination of knowledge and skills as opposed to uniform mass education of the industrial age. The acceleration of the perpetual change with the society and the economy makes it common for quite a few to change their jobs or carriers several times during their productive life. Requalification becomes easier if the educational opportunities at earlier stages really provide generic education, not just professional training tailored to a specific job (note that even the information-society motivation need not mean that "computers to every classroom" is really a good idea, given how incomplete our knowledge of the efficiency and effects of the extensive use of computers actually is [42]). This may increase the value of foundational disciplines within the educational system.

\section{Social consequences}

The organizational elements of computing and communication systems provide a metaphor for organizational structures in the knowledge-based society 
and the intelligent enterprises (see also [50] on this), and Paul Baran's [2] ideas about decentralized, self-reconfigurable networks of autonomous agents come close to a blueprint for liberal democracy as opposed to heavily centralized structures of telecommunication monopolies of his time. Even though this does not mean that the society will become computer-controlled or that the enterprises will be run by robots, the parallels may serve as a mind opener which unleashes our creativity to find new solutions that match the future possibilities better, the principles of which have only been enabled by the new technological basis of the society.

The trade-off between the value of hardware and software closely parallels that between manufacturing and agriculture combined and the knowledgebased sectors of modern society. The digital (or information) paradigm is the basis of these trends of both of these cases, and it is as possible for a society to be based on the intangible activities (which gain relevance once the basic material needs of humans are sufficiently covered by the existing technologies), as it is the case with computer systems. The cost of difference disappears, and the difference is actually becoming more a virtue than an obstacle (socially the uniform workforce is no longer needed in order to suit the basic material needs, and similarly the value of software components depends on the ideas, not some uniform components). The open society integrates for differences and facilitates to function with less rigidity of thought, less constraints for development and more interconnected world. The rationales for open software systems provide essentially the same motivations (the more parties can join in, the more benefit for everybody) as the liberal economy theories. Mobility, both physical and social, has contributed to these social tendencies, as well as networking has motivated some of the key efforts within the systems area. Ubiquitous computing and zero-cost high-bandwidth networking will contribute to either of these, as more and more social economic functions will be based on the virtual basis.

The implications for the political structures will have to surface up as well, even though the lessons of the twentieth century give strong reasons for caution. The hierarchical structure of representative democracy is based on obsolete communication channels, and some of its properties are clearly not able to respond in reasonable time to changes around, as well as enterprises with obsolete bureaucracies are unable to compete with flexible information-based companies running more efficient matrix, team-organized or ad-hocratic forms of organization. The shared/conflicting responsibility modes of function will find its way into social and political structures in order to synchronize better with the pace of the world ([55], [58], [12], or [46]). The naîve proposals of "electronic town hall" in Ross Perrot direct democracy style are unlikely to function, and some sophisticated way of representation, organization of intermediation, and reorganization of "virtual" voting districts in a way immune to gerrymandering will have to be designed [3]. Networks may help to overcome boundaries between groups which would otherwise have communication difficulties. Another aspect worth mentioning is the urge for politics to remove interference 
with technology and human creativity as much as possible-current regulatory frameworks often clash with inventing new things (e.g., digital convergence does not fit regulatory frameworks of separate licensing of telecommunication services).

\section{The Internet and beyond}

The success of the Internet is based on the success of a decentralized and distributed effort of many agents loosely coordinated by a loosely drafted set of open quasi-standards. A few years ago the "serious" business world would not pay much attention to a bunch of idealistic academics. Only at about the same time when NFSNET has stopped to function as an Internet backbone and Internet was "privatized" in a way (1994), the business world has begun to take it for real ${ }^{7}$. According to the host count performed by Network Wizards, www. nw. com, in July 1997 there have been 19,540,000 Internet hosts worldwide in 1,301,000 domains and 171 countries, making Internet the worldwide network (just a year ago, Internet was trailing UUCP which was then still 17 countries ahead). When combined with population figures (see Table 1 for OECD countries and July 97 host count), the diffusion of the Internet is highest in the Scandinavian countries, U.S., New Zealand, and Australia where the penetration figures are within 65.77 hosts per 1000 inhabitants for Finland, to 26.21 for Denmark (the U.S. ranks third with 44.97 hosts per 1000 inhabitants). Although the differences in penetration levels look quite huge for some countries (e.g., 14.98 for the U.K, 5.02 for France, or 4.75 for the Czech Republic), the absolute time difference is just a few years because of the exponential growth (Finland had penetration level of today's U.K. some 2.4 years ago, of France 4.2 years, and of the Czech Republic 4.3 years ago; the relative difference of the last two being just about 8 weeks) $)^{8}$. The WWW server count is estimated to 1,269,800 according to the statistics in [62] (see Figures 1 and 2 for the statistics of Internet host and WWW server counts from this reference), having grown from zero since 1993 introduction of http protocol by Tim Berners-Lee at CERN.

Some of the most ambitious undertakings are under way right now, whose realization should mean a considerable step forward along the vector of future trends. The Net will be the place where these effects are going to be visible most. Digitization of telecommunications and deregulatory efforts should put us closer to omnipresent bandwidth for negligible price. Several

\footnotetext{
${ }^{7}$ By that time, NFSNET Internet backbone traffic exceeded 10 Tbytes/month. Bill Gates would not think Internet deserved much space in his [16] until second edition appeared within less than a year. U.S. telecoms would similarly wait until 1996 to ask U.S. Congress to ban Internet telephony, about one year after it had become available (unsuccessfully, so in mid-1997, several major telecoms already announced they would offer Internet telephony as part of their services, in the if you can't beat them, join them style).

${ }^{8}$ Or taken the other way around, these figures show how fast the clock of change is running.
} 
major large-scale Gigabps networks are currently being built, which present testbeds for future global-scale attempts. One of those is the Internet 2 consortium of the U.S. universities building a 2.5 Gbps network which should provide a successor of the Internet with qualitatively new functionality (see http://www.internet2.edu), and also provide new technology for the National Information Infrastructure [8]. Another unlikely competitor to these ambitious goals is the Multimedia Super Corridor project of the Malaysian government aiming at creating a 2.5 Gbps-based infrastructure in a $40 \mathrm{~km}$ per $15 \mathrm{~km}$ area around Kuala Lumpur, providing advanced infrastructure for for both the commercial institutions and by then a fully paper-less government before 2020 ([28], or see http://www.mdc. com.my/msc/).

The growth of the Net is definitely the most important technical and infrastructural discontinuity conceived by the information revolution. The exponential growth self-enforces its base along the law of increasing returns, and within the last few years we are witnessing the emergence of a (virtual) global community. Any society depends on interaction among its members, and hence it should not come as a surprise that it is not merely an "information economy" but to more extent even a "network economy" [33] which reinforces the foundations of the Information Society.

On a micro-level of social interactions, the Net and the advanced telecommunications bring new codes of behavior, aspiring to become a norm within the society segments larger than the initial set of network pioneers. Besides of benefits, unexpected friction appears such as the phenomenon of "flaming" (documented quite early after the e-mail communication started to be used [52], [29]), or etiquette problems with beeping cellular phones at theater performances or during religious services. MUDs, MOOs and other rôle-playing communication-based tools can be useful for unleashing the imagination and stimulating a creative environment free of real-world psychological obstacles [55]. Conceptualization of some of the consequences of electronic communications, teleworking tools, and the loss of emotional clues in inter-personal communications may, however, be very difficult to explain, as demonstrated, e.g., in [36].

\section{Some of the problems ahead}

The development of information and communication technology and the computer science advances in the architecture of software and network systems make it possible to fulfill the promise of Global Information Society. The remaining technological and scientific challenges cannot be underestimated, but the main problems ahead of us are related to the societal concerns and implications which are network-related.

The information revolution brings about another shake-up which is going to change the balance of power worldwide, and within the society, too. The speed with which it is happening tends to amplify differences, and the danger of creating an under-privileged class of information "have-nots" may be real. 
Deregulation of telecommunications becomes a reality-digital technology has made the concept of natural monopoly obsolete, advances in convergence of communication technologies are impossible within the majority of the current regulatory frameworks, and last but not least, increased competition is driving communication costs down ${ }^{9}$ (cf. [9]). The notion of "universal service", a level of telecommunication service for which efforts should be made so that it is accessible to every member of the society, is being scrutinized, and serious proposals already appeared advocating inclusion of e-mail into delivery mechanisms, working as universally as the delivery of paper mail [1].

The attempts to regulate Internet as if it were a broadcast medium threaten to undercut the innovative potential which has so far worked so well. Recent defeat of Communications Decency Act (part of the U.S. Telecommunications Act of 1996) by unanimous vote of the U.S. Supreme Court followed by the publication of the plan of the Clinton administration to establish a free zone for electronic commerce and to refrain from imposing additional regulation or taxes [61] (but compare [6], also reflected in [27], for arguments favoring introduction of a "bit tax" as an analogy to VAT, once sending bits is generally acknowledged as a common economic activity). Several governments have introduced Internet censorship laws ranging in their effect from establishing governmentcontrolled access points, designating Internet a broadcast medium or controlling cryptography, to including censorship as legal measures of a more general scope. Legal problems which need to be solved in connection with the Internettype means of communication include the problem of classification of this type of media, solving territoriality problems in some way, and to overcome national legislation attempts to tackle a problem which clearly transgresses national boundaries and national soverenity. Until some agreement similar to the regulation of high seas or cosmic space have been reached, no legal framework will be completely adequate. Mankind will have to find some way of living in a world in which certain pieces of information are already public property, even though it would have been better it they never had existed (such as bomb construction, etc.)

Electronic commerce faces advances in availability of cryptography and identity verification systems in order to really start off the ground. It is likely that even the current Internet is still the safest place where to use your credit card (it is still much more difficult to monitor your electronic transactions and to extract card numbers, etc., than to break into your house and get it physically), but wider use of cryptography methods can make it even safer - e.g., the vendor who accepts a card payment need not be able to decipher even the card number which may be passed through him to the bank still in encrypted form. Digital money is another concept which is more natural than

\footnotetext{
${ }^{9}$ The general expectation is a fall in long-distance communication cost by $80 \%$ within 5 years after deregulation. The estimates of total annual benefits of the U.S. Telecommunications Act of 1996 are likely to exceed $\$ 50$ billion, compared to $\$ 16-23$ billion consumer and businesses annual benefits coming from Airline Deregulation Act of 1978, according to U.S. Commerce Committee staff estimates and [60].
} 
traditional paper banknotes once computer becomes ubiquitous. After all, virtual banking will hardly be able to handle paper money. The dark side of the ubiquitous computer and the benefits of globalization will be the impossibility to shield any part of the world away from transfers of huge sums within fractions of second around the globe, potentially causing instabilities within the soft-economy-based world. New models of financing will have to appear which would be applicable to paying for information services over the nets such as per-use micropayments.

Within the interconnected world, the threats to individual privacy protection are paramount, and protection mechanisms should be built into key systems at very elementary level. In fact the privacy-protection principles may be a candidate for a set of laws which would be built into every single chip, and very likely with much more urgency than Asimov's laws of robotics. It may come as a paradox, but not only privacy-protection mechanisms are needed, but on the other hand, also reliable identity verification mechanisms are needed once more and more transactions and interactions will move into Cyberspace.

\section{Conclusion}

The Information Society concept is hardly a well-defined technical artifact, or an engineering blueprint for a technology-based future. The causes and effects are vaguely defined, and sometimes they fuse and melt together, as the "virtuous cycles" [51] of positive feedback based on the law of increasing returns keep generating exponential growth. No matter how loosely defined they may have been by the time of their dawn, the concepts of agricultural and industrial societies and the revolutionary changes which triggered them off are clearly visible as a sum of the technological and social changes happening on a large scale and generating irreversible change.

A clearer picture can only be seen from a distance. The metrics of our understanding requires to step outside of a set of bits and pieces, in order to be able to generate concepts which move us closer to each member of such a set. Some of the analogies we use when contemplating the changes which the digital and network revolution generates today, are most likely flawed to some extent, and some details of the large picture will perhaps have to be modified or adjusted. The experience of changes happening over past decades, however, do not leave much room for doubts about the picture at large.

The Information Society is also a metaphor for describing the synergy between technological and social changes. The mood associated with it at the end of the millennium is that of anxiety of change, infinite possibilities and new frontiers of the digital world, quite unlike the feeling that classical mechanics had been providing all the answers within the world defined by its physical/material side. As it is with every metaphor, neither this one can be taken verbatim. Sure, no matter how small chips we make, the theoretical limits based on mathematics won't be lifted away, and neither will be the effective barriers coming from the limitations which computability theory or complexity theory 
can prove. The technological metaphor does nonetheless play the rôle of an enabler, magnifier, multiplier, generator, or mind opener. It allows human creativity to assume new grounds and to move closer (perhaps asymptotically) to fulfilling the vision which is generated by it.

Given the speedup of technological advances we are witnessing today, the Information Society cannot possibly be very far away. In a way, it is sufficient to flow with the tidal waves of changes-and (one should not forget this) keep generating the very same waves by ourselves.

\section{References}

1. Robert H. Anderson, Tora K. Bikson, Sally Ann Law, and Bridger M. Mitchell: Universal Access to E-Mail: Feasibility and Societal Implications. Center for Information evolution Analyses, RAND, Santa Monica, CA, 1995.

2. Paul Baran: On Distributed Communications, RAND Corporation, Santa Monica, CA, 1968.

3. John Seely Brown, Paul Duguid, and Susan Haviland: Towards Informed Participants: Six Scenarios in Search of Democracy in the Electronic Age, in: David Bollier, rapporteur: The Promise and Perils of Emerging Information Technologies, The Aspen Institute, Washington, D.C., 1993.

4. James M. Buchanan: Politics by Principle, Not Interest. Cambridge University Press, Cambridge, MA, 1997. (forthcoming)

5. Commission on National Investment on Higher Education: Breaking the Social Contract. The Fiscal Crisis in Higher Education. Council for Aid to Education, RAND Corporation, Santa Monica, CA, June 1997.

6. Arthur J. Cordell: Taxing the Internet: The Proposal for a Bit Tax, Journal of Internet Banking and Commerce, Vol 2, No. 2, March 1997, http://www. arraydev.com/ /commerce/JIBC/articles.htm.

7. Computer Science and Telecommunications Board: Information Technology in the Service Society. A Twenty-First Century Lever, National Academy Press, Washington, 1994.

8. Computer Science and Telecommunications Board: Realizing the Information Future. The Internet and Beyond. National Academy Press, Washington, 1994.

9. Computer Science and Telecommunications Board: The Changing Nature of Telecommunications/Information Infrastructure. National Academy Press, Washington, 1995.

10. Stan Davis and Bill Davidson: Vision 2020. Simon\&Schuster, New York, 1991.

11. Stan Davis: Future Perfect. Tenth Anniversary Edition. Addison-Wesley, Reading, MA, 1996.

12. Michael Dertouzos: What Will Be, HarperEdge, New York, 1997.

13. Peter F. Drucker: Post Capitalist Society. HarperCollins, New York, 1993.

14. Daniel Druckman, Jerome E. Singer, and Harold Van Cott, eds.: Enhancing Organizational Performance, National Academy Press, Washington, 1997.

15. Francis Fukuyama: Trust. The Social Virtues and the Creation of Prosperity. The Free Press, New York, 1995.

16. Bill Gates, with Nathan Myhrvold and Peter Rinearson: The Road Ahead. Viking, New York, 1995.

17. Amy Korzick Garmer and Charles M. Firestone: Creating a Learning Society. Initiatives for Education and Technology. The Aspen Institute, Washington, D.C., 1996. 
18. George Gilder: Telecosm. Simon\&Schuster, to be published, chapters have been appearing in Forbes ASAP since December 7, 1992.

19. Jeremy Greenwood and Mehmed Yorukoglu: 1974. Working Paper No. 429, Rochester Center for Economic Research, University of Rochester, Rochester, NY, September 1996.

20. Jeremy Greenwood: The Third Industrial Revolution. Working Paper No. 435, Rochester Center for Economic Research, University of Rochester, Rochester, NY, October 1996.

21. Jozef Gruska, Ivan M. Havel, Juraj Wiedermann, and Jaroslav Zelený: Počítačová revolúcia ("Computer revolution", in Slovak and Czech), Proc. Sofsem'83, Ždiar, 1983, pp. 7-64.

22. Jozef Gruska and Roland Vollmar: Towards Adjusting Informatics Education to Information Era. FIMU-RS-97-03 technical report, Faculty of Informatics, Masaryk University, Brno, 1997, 33pp.

23. Katie Hafner and Matthew Lyon: Where Wizards Stay Up Late. The Origins of the Internet. Simon\&Schuster, New York, N.Y., 1996.

24. John Hagel III and Arthur G. Armstrong: Net Gain. Expanding markets through virtual communities. Harvard Business School Press, Boston, MA, 1997.

25. Douglas E. Harris, ed.: Organizational Linkages. Understanding the Productivity Paradox, National Academy Press, Washington, 1994.

26. Paul T. Hill, Lawrence T. Pierce, and James W. Guthrie: Reinventing Public Education. How Contracting Can Transform America's Schools. A RAND Research Study. The University of Chicago Press, Chicago, 1997.

27. High-Level Expert Group: Building the European Information Society for us all. Final policy report. European Commission, April 1997.

28. Derrik Khoo: The Multimedia Super Corridor: An Island of Excellence. Business Times Annual 1997, Business Times Malaysia, 1997, pp. 64-67.

29. Sara Kiesler, Jane Siegel, and Timothy W. McGuire: Social Psychological Aspects of Computer-Mediated Communication, American Psychologist, 39 (October), 1984, pp. 1123-1134.

30. John Leslie King: Where Are the Payoffs from Computerization? Technology, Learning, and Organizational Change, in: [31], pp. 239-260.

31. Rob Kling, ed.: Computerization and Controversy. Value Conflicts and Social Choices. Academic Press, San Diego, CA, 2nd ed., 1996.

32. Rob Kling and Jonathan P. Allen: Can Computer Science Solve Organizational problems? The Case for Organizational Informatics, in: [31], pp. 261-276.

33. Kevin Kelly: New Rules for the New Economy, Wired, 5.09, September 1997, pp. 140-197.

34. Thomas K. Landauer: The Trouble With Computers. Usefulness, Usability, and Productivity. MIT Press, Cambridge, MA, 1996.

35. Don Mankin, Suzan G. Cohen, Tora K. Bikson: Teams and Technology. Fulfilling the Promise of New Organization, Harvard Business School Press, Boston, MA, 1996.

36. M. Lynne Markus: Finding a Happy Medium: Explaining the Negative Effects of Electronic Communication on Social Life at Work, ACM Transactions on Information Systems, 12(2), April 1994, pp. 119-149.

37. Nathan Associates: Building an Information Economy. Business Software Alliance, June 1997.

38. National Comittee of Inquiry into Higher Education: Higher Education in the Learning Society: Report of the National Comittee. Norwich, 1997.

39. Nicolas Negroponte: Being Digital, Alfred A. Knopf, New York, 1995. 
40. Ikujiro Nonaka and Hirotaka Takeuchi: The Knowledge-Creating Company. Oxford University Press, Oxford, 1995.

41. OECD Committee for Information, Computer and Communications Policy: Global Information Infrastructure - Global Information Society (GII-GIS). Policy Requirements. OECD/GD(97)139 Report, OECD, Paris, 1997.

42. Tod Oppenheimer: The Computer Delusion, The Atlantic Monthly, July 1997.

43. W. W. Powell: Neither market nor hierarchy: Network forms of organizations. In: B. M. Starr and C. C. Cummings, eds.: Research in Organization Behavior, Vol. 12, JAI Press, Greenwich, CT, 1990.

44. James Brian Quinn: Intelligent Enterprise, A Knowledge and Service Based Paradigm for Industry, The Free Press, New York, 1992.

45. Howard Rheingold: The Virtual Community: Homesteading on the Electronic Frontier. Addison-Wesley, Reading, MA, 1993.

46. Christopher Rowe: People and Chips: The Human ilmplications of Information Technology. Alfred Waller, Henley-on-Thames, 2nd ed., 1990.

47. Robert Rowthorn and Ramana Ramaswamy: Deindustrialization: Causes and Implications. IMF Working Paper WP/97/42, April 1997.

48. Peter H. Salus: Casting the Net. From ARPANET to INTERNET and beyond... Addison-Wesley, Reading, MA, 1995.

49. Stephen Saxby: The Age of Information. The Macmillian Press, London and Basingstoke, 1990.

50. Jorge Reina Schement and Terry Curtis: Tendencies and Tensions of the Information Age. The Production and Distribution of Information in the United States. Transaction Publishers, New Brunswick, N.J., 1995.

51. Peter Schwartz and Peter Leyden: The Long Boom: A History of the Future 19802020, Wired, 5.07, July 1997, pp. 115-173.

52. Norman Z. Shapiro and Robert H. Anderson: Toward an Ethics and Etiquette for Electronic Mail. RAND report R-3283-NSF/RC, Santa Monica, CA, 1985.

53. Daniel A. Sichel: The Computer Revolution. An Economic Perspective. Brookings Institution Press, Washington, D.C., 1997.

54. Paul A. Strassmann: The Squandered Computer. Evaluating the Business Alignment of Information Technologies. The Information Economics Press, New Canaan, CT, 1997.

55. Don Tapscott: The Digital Economy, Promise and Peril in the Age of Networked Intelligence, McGraw-Hill, New York, 1996.

56. John Tiffin and Lalita Rajasingham: In Search of the Virtual Class. Education in an Information Society. Routledge, London and New York, 1995.

57. Alvin Toffler: The Third Wave, William Morrow and Co., 1980.

58. Alvin Toffler and Heidi Toffler: Creating a New Civilization: The Politics of the Third Wave, Turner Publishing, Atlanta, VA, 1995.

59. Jerry Useem: Churn, Baby, Churn. Inc. magazine, State of Small Business issue, 1997, p. 25.

60. C. Winston: Economic Deregulation: Days of Reckoning for Microeconomists, Journal of Economic Literature, Vol. 31, No. 3, September 1993, pp. 1263-1289.

61. Working Group on Electronic Commerce: A Framework for Global Electronic Commerce, The White House, Washington, D.C., July 1997.

62. Robert H. Zakon: Hobbes' Internet Timeline. http://info.isoc.org/guest/zakon/ /Internet/History/HIT.html, September 1997.

63. Jiří Zlatuška: Education as an Information-Age Business. in: J. Hlavička and K. Květoň, eds.: Proc. of the Rôle of the Universities in Future Information Society conference (RUFIS'97), ČVUT, Prague, September 25\&26, 1997, pp. 49-56. 


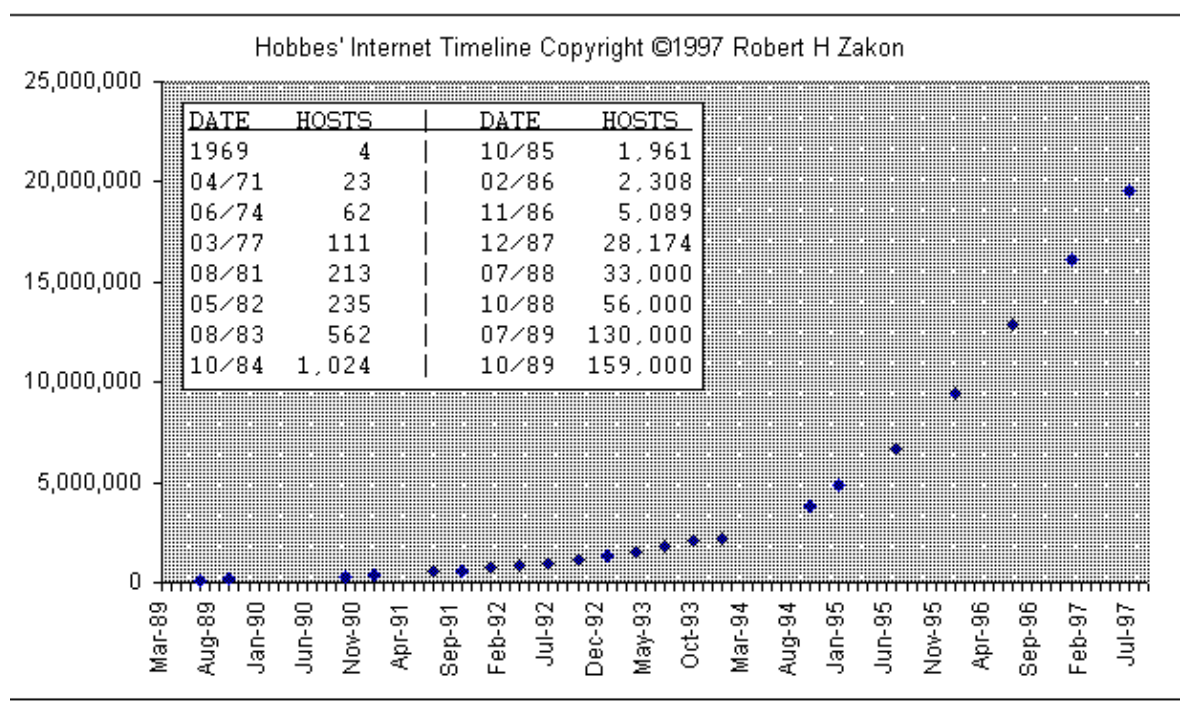

Figure 1: Internet host count

(http://info.isoc.org/guest/zakon/Internet/History/HIT.html)

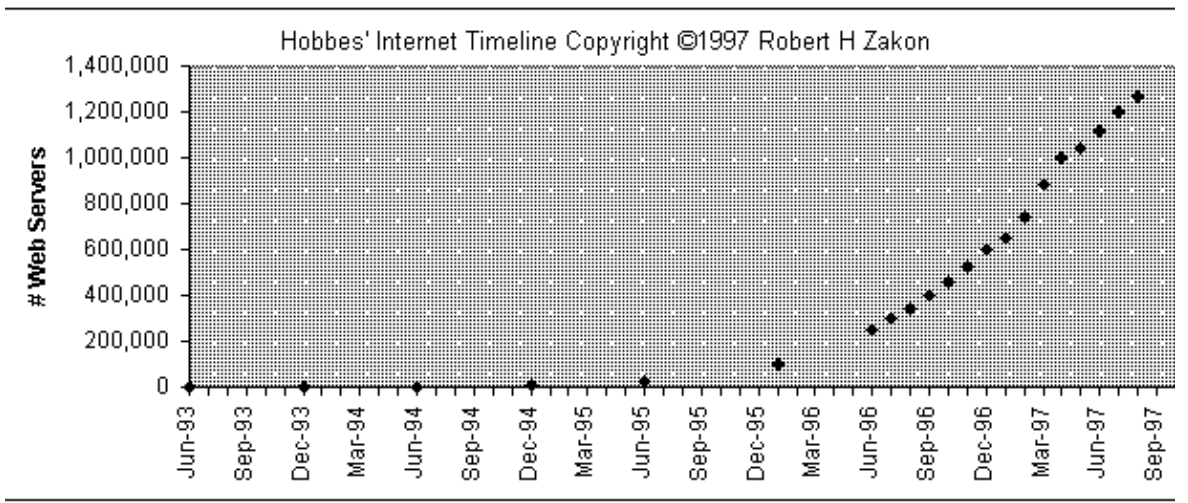

Figure 2: WWW server count

(http://info.isoc.org/guest/zakon/Internet/History/HIT.html) 


\begin{tabular}{lrrrrrrr}
\hline Country & \multicolumn{1}{c}{ July 91 July 92 } & July 93 & July 94 & July 95 & July 96 & July 97 \\
\hline Finland & 1.74 & 3.12 & 5.34 & 9.75 & 21.90 & 54.27 & 65.77 \\
Iceland & 0.75 & 1.53 & 4.75 & 12.24 & 25.47 & 40.49 & 53.01 \\
Norway & 1.94 & 3.35 & 5.83 & 8.94 & 15.28 & 27.70 & 47.95 \\
USA & 1.69 & 2.87 & 4.87 & 7.84 & 16.23 & 31.26 & 44.97 \\
New Zealand & 0.35 & 0.53 & 0.91 & 4.21 & 12.25 & 21.76 & 43.48 \\
Australia & 1.26 & 2.78 & 4.65 & 7.15 & 11.49 & 22.02 & 33.44 \\
Sweden & 1.37 & 2.43 & 3.61 & 6.07 & 12.09 & 21.11 & 32.23 \\
Denmark & 0.30 & 0.53 & 1.19 & 2.33 & 7.07 & 14.72 & 26.21 \\
Canada & 0.69 & 1.37 & 2.45 & 4.36 & 8.87 & 14.33 & 23.32 \\
Netherlands & 0.49 & 1.39 & 2.33 & 3.88 & 8.76 & 13.89 & 22.10 \\
Switzerland & 1.46 & 2.50 & 4.42 & 6.78 & 9.01 & 14.50 & 20.90 \\
U.K. & 0.12 & 0.65 & 1.54 & 2.67 & 4.97 & 9.89 & 14.98 \\
Austria & 0.27 & 0.82 & 1.47 & 2.51 & 5.06 & 8.83 & 10.86 \\
Germany & 0.26 & 0.54 & 1.13 & 1.83 & 4.29 & 6.71 & 10.72 \\
Luxembourg & - & 0.21 & 0.47 & 1.06 & 3.67 & 6.97 & 9.33 \\
Ireland & 0.03 & 0.18 & 0.48 & 0.93 & 2.78 & 6.00 & 9.23 \\
Belgium & 0.03 & 0.15 & 0.43 & 1.20 & 2.34 & 4.27 & 8.49 \\
Japan & 0.05 & 0.13 & 0.29 & 0.58 & 1.28 & 3.96 & 7.63 \\
France & 0.16 & 0.33 & 0.69 & 1.24 & 1.96 & 3.26 & 5.02 \\
Czech Republic & - & 0.06 & 0.26 & 0.55 & 1.44 & 3.12 & 4.75 \\
Italy & 0.03 & 0.09 & 0.26 & 0.41 & 0.81 & 1.99 & 3.70 \\
Hungary & - & 0.00 & 0.14 & 0.53 & 1.10 & 2.45 & 3.30 \\
Spain & 0.03 & 0.09 & 0.22 & 0.54 & 1.02 & 1.59 & 3.11 \\
Korea & 0.00 & 0.10 & 0.12 & 0.30 & 0.50 & 1.10 & 3.00 \\
Greece & 0.02 & 0.06 & 0.13 & 0.28 & 0.53 & 1.21 & 1.88 \\
Portugal & - & 0.13 & 0.20 & 0.46 & 0.88 & 1.77 & 1.83 \\
Poland & - & 0.02 & 0.09 & 0.19 & 0.41 & 1.00 & 1.12 \\
Mexico & 0.00 & 0.00 & 0.02 & 0.06 & 0.09 & 0.22 & 0.39 \\
Turkey & - & - & 0.00 & 0.02 & 0.05 & 0.13 & 0.37 \\
\hline & & & & & & &
\end{tabular}

Table 1: Diffusion of Internet hosts in OECD countries per 1000 inhabitants For 1996 and 1997, population figures from 1995 have been used; U.S. hosts include edu, com, gov, mil, org, net, and us.

Source: [41] and Network Wizards at http://www.nw.com/ 